\title{
Familial Aggregation of Non-Hodgkin's Lymphoma (NHL). A Case Report
}

\author{
Sandra S.C.M. Loves', Lieuwe de Haan², Simon M.G.J. Daenen ${ }^{3}$ \\ Department of Internal Medicine, Rijnstate Hospital Arnhem, Arnhem, The Netherlands; ${ }^{2}$ Department of Internal Medicine, Scheper Hospital Emmen, Emmen, \\ The Netherlands; ${ }^{3}$ Department of Haematology, University Medical Centre Groningen, Groningen, The Netherlands
}

Key words: non-Hodgkin's lymphoma, familial lymphoma, haematological cancer, genetic susceptibility, risk factors

Corresponding author: Sandra Loves, Department of Internal Medicine, Rijnstate Hospital Arnhem, P0 Box 95556800 TA Arnhem, The Netherlands, tel.: +31 (0)26-3787750,fax: +31 (0)26-3786737,e-mail: sloves@alysis.nl

Submitted: 25 April 2006

Accepted: 2 August 2006

\begin{abstract}
A family is reported in which three male siblings of Asian descent developed non-Hodgkin's lymphoma (NHL). Case 1 was diagnosed with indolent follicular lymphoma stage IIIA at age 45. Case 2 presented with large B-cell lymphoma stage IIB at age 56. Chromosomal investigation of the peripheral blood did not show abnormalities. Chemotherapy induced a complete remission. However, after a period of nearly ten years he developed acute myeloid leukaemia. Case 3 developed large B-cell lymphoma stage IVA at age 52. Cytogenetic analysis in peripheral blood was normal. Shared genetic and environmental risk factors remain to be identified in this family. Familial aggregation of $\mathrm{NHL}$ is uncommon. In some families, various forms of immunodeficiency have been found. In addition to coincidental clustering of cases, and rare cases explained by known tumour syndromes such as Li-Fraumeni (like) syndrome, other familial cases may share as yet unknown genetic and/or environmental risk factors.
\end{abstract}

\section{Introduction}

In Western countries there has been a large and mainly unexplained rise in incidence of non- Hodgkin's lymphoma (NHL) in recent years [1]. Several aetiological factors for NHL are known, including genetic and environmental or occupational factors. Familial aggregation of lymphoproliferative malignancies (malignant lymphoma and lymphatic leukaemia) has been reported repeatedly but accounts for only a small proportion of lymphoma cases. Most of the familial cases are sibling pairs either alone or in combination with other affected relatives. A population-based study in Israel among first-degree relatives of patients with lymphomas showed that only $0.7 \%$ of the lymphoma patients had a history of lymphoma in one or more relatives [2]. In some families, a pre-existing immune deficiency has been described [3-5]. No histological subtype appears to predominate in familial cases.

Here, a family in which all three living male siblings of Asian descent developed NHL is presented.

\section{Case reports}

\section{Case 1}

This patient was born in 1936 in East Java (Indonesia), as were his three younger brothers. His father worked as a tea planter and died in 1944 at age 38 in a prisoner-of-war camp. A younger brother also died in a prisoner-of-war camp at age 6. In East Java there was no overt pollution. In 1957 the remaining three brothers and their healthy mother emigrated to the Netherlands. The patient worked as a technical 
chemist. He smoked forty pack years and had always been healthy until 1981 when follicular lymphoma stage IIIA was diagnosed at age 45 . He was treated with twelve cycles of COP (cyclophosphamide, oncovin and prednisone). In 1994 he developed a relapse of his indolent lymphoma with mediastinal and abdominal localization for which again COP chemotherapy was given. In 1997 a second relapse of his lymphoma with mediastinal localization was noted. Once more the COP regimen was started which induced a complete remission. At present he is well without evidence of recurrent lymphoma.

\section{Case 2}

The second living brother was born in 1937. In the Netherlands he worked as a construction fitter visiting several factories. He also smoked (approximately twelve pack years) and had always been healthy until December 1993 when at age 56 diffuse large B-cell lymphoma (DLBCL) was diagnosed, stage II A with localizations in the axilla, cervical region and nasopharynx. Primary treatment consisted of six cycles of CHOP (cyclophosphamide, oncovin, adriamycine and prednisone), which resulted in a complete remission. No additional therapy was given. In July 2003 he presented with weight loss, fever and enlarged cervical glands. Acute myeloid leukaemia was diagnosed. The leukaemia was treated with daunorubicine and cytarabine followed by a course of high-dose cytarabine. After an initial response a relapse of his leukaemia occurred in July 2004. At the moment he is being treated on an experimental basis. Chromosomal investigation in peripheral blood has been performed without finding any abnormalities.

\section{Case 3}

The third living brother was born in 1942. As a technician he worked with acids, alkalis, cyanide and metals. He smoked eight pack years and was well until March 2004 when DLBCL stage IVA was diagnosed with paravertebral localization and myelum compression causing neurological symptoms. There was also bone marrow involvement. He was treated initially with $\mathrm{CHOP}$ chemotherapy, in total eight cycles, followed by rituximab infusions, four cycles. He responded very well. CT-scan showed a complete regression of the paravertebral mass. Bone marrow biopsy, however, revealed a sporadic focus of lymphoma. Chromosomal investigation of the peripheral blood did not show abnormalities.

Unfortunately, three months after completion of the therapy he developed a relapse with cervical and retroperitoneal localizations. Simultaneously he was diagnosed with right-sided oculomotor nerve palsy. Neurological examination, including CT and MRI of the brain, did not reveal meningeal involvement but the cerebrospinal fluid was positive for lymphoma cells. He was referred for further second-line chemotherapy.

The family history was unremarkable for other types of cancer and did not meet clinical criteria for $\mathrm{Li}$ Fraumeni syndrome or any of the other known human tumour syndromes. There were no symptoms to suggest immunodeficiency in this family.

\section{Discussion}

Risk of NHL has been found significantly increased in relatives of people with haematological malignancies, especially among siblings, although the absolute risk is small $[2,6,7]$. It has been estimated that the absolute lifetime risk for a first-degree relative of an $\mathrm{NHL}$ case of developing $\mathrm{NHL}$ is $3.6 \%$ (compared with a population risk of $2.1 \%$ ) and higher if the index case had an aggressive subtype of $\mathrm{NHL}$ [8]. Aggregation of $\mathrm{NHL}$ seems to be stronger for siblings and for male relatives and among relatives of early-onset ( $<50$ years) $\mathrm{NHL}$ cases [9]. With the exception of chronic lymphocytic leukaemia and indolent lymphoma, most affected families present with diverse lymphoproliferative and other haematological malignancies [10]. This diversity is not completely unexpected as lymphoma and leukaemia have common cellular origins, and some types have common genetic somatic changes or share common aetiological factors. Histological subtypes do appear to have an effect on familial risk. A recent study using the Swedish Family-Cancer Database calculated standardized incidence ratios (SIRs) for histopathology-specific subtypes of $\mathrm{NHL}$ in offspring with $\mathrm{NHL}$ whose parents or siblings were affected with different types of lymphoproliferative malignancies. A family history of NHL significantly increased the risk for NHL (SIRparent=1.8; SIRsibling = 1.9) and for diffuse large B-cell lymphoma (SIRparent=2.3), follicular lymphoma (SIRsibling=2.3), and B-cell lymphoma not otherwise specified (NOS) (SIRsibling=3.4). For a parental history of histopathologyspecific concordant cancer, the risks were significantly increased for diffuse large B-cell lymphoma (SIR=1 1.8), follicular $\mathrm{NHL}(\mathrm{SIR}=6.1)$, plasma cell myeloma $(\mathrm{SIR}=2.5)$, and chronic lymphocytic leukaemia $(S I R=5.9)$ [11].

In general, familial aggregation of lymphoproliferative malignancies may be coincidental or may be caused by (combinations of) shared genetic and environmental risk factors. In rare cases, familial aggregation is associated 
with rare hereditary tumour syndromes such as Li-Fraumeni syndrome or hereditary immunodeficiency syndromes. Apart from those cases occurring in families meeting the criteria of Li-Fraumeni (like) syndrome, constitutional p53 mutations are rare in cases of familial aggregation of lymphoma [12]. Some multiple-case families have been found to have various types of immune deficiency disorders $[3,4]$. The immunological disorders range from X-linked lymphoproliferative syndrome and ataxia telangiectasia to subtle laboratory findings like a disturbance in T cell function, decreased T cell number, or increased immunoglobulins. In other families risk factors are unclear. An argument in favour of genetic predisposition playing a role is the fact that various investigators have demonstrated that anticipation is present in familial NHL $[13,14]$. Anticipation is a phenomenon characterised by an increase in severity of clinical symptoms or a decrease in the age of onset in successive generations. A possible non-genetic explanation is that the parents and children have been simultaneously exposed to a causative environmental agent, the difference in age of onset reflecting the generational difference. However, this does not explain cases in families who did not live together and cases where parents were diagnosed with $\mathrm{NHL}$ many years after their children were.

A population-based case-control study in the United States showed that certain non-genetic risk factors, including exposure to a chlorinated hydrocarbon pesticide, plywood, fibreboard or particleboard and history of liver diseases (other than hepatitis or cirrhosis) $(\mathrm{OR}=6.5,95 \% \mathrm{Cl}: 1.2-36.2)$, increased the risk of $\mathrm{NHL}$ in patients with a family history of haematological malignancies compared to patients without such family history [15]. Another study could not confirm that a family history of cancer modifies the association of agricultural exposures with NHL [16] and a more recent study showed no evidence that aetiological associations varied between familial NHL and nonfamilial NHL cases [7]. In general, it is therefore still difficult to pinpoint interactions between shared inherited and environmental risk factors with respect to $\mathrm{NHL}$ development.

In the present family, no signs of impaired immunity were present; however, neither cancer predisposing germline gene mutations nor exposure to viruses or environmental carcinogens can be excluded. All three affected brothers may have been exposed to possible carcinogenic materials during work, and all three were smokers. Tobacco use has been suggested to increase the risk of $\mathrm{NHL}$, but the results of epidemiological studies have been inconsistent [17]. The combined effects of genetic susceptibility and tobacco use could possibly lead to NHL. At diagnosis, one brother had indolent lymphoma and two had aggressive lymphoma of follicle centre cell origin. It is possible that this was a transformed lymphoma, which originated also from an indolent lymphoma, but this could not be substantiated by available clinical and morphological data. The leukaemia of case 2 could have been secondary to chemotherapy or could have been a second primary haematological malignancy, which would then again suggest possible predisposition.

In conclusion: in this case report we have presented a quite remarkable clinical finding in three male siblings who developed malignant lymphoma. All of them are still alive. Shared genetic or environmental risk factors, or combinations of these, remain to be identified in this family.

\section{Acknowledgement}

The authors thank B.P.M. Imholz, MD, PhD, for providing medical information on Case 1.

\section{References}

1. Swerdlow AJ. Epidemiology of Hodgkin's disease and nonHodgkin's lymphoma. Eur J Nucl Med Mol Imaging 2003; 30 (suppl 1): S3-S12.

2. Paltiel O, Schmit T, Adler B, Rachmilevitz EA, Polliack A, Cohen A, Haim N, Shachar MB, Epelbaum R, Barchana M, Cohen R and Ben Yehuda D. The incidence of lymphoma in first-degree relatives of patients with Hodgkin disease and non-Hodgkin lymphoma. Cancer 2000; 88: 2357-2366.

3. Linet MS and Pottern LM. Familial aggregation of hematopoetic malignancies and risk of non-Hodgkin's lymphoma. Cancer Res (suppl) 1992; 52: 5468-5473.

4. Clark JW, Tucker MA and Greene MH. Clinical and laboratory observations in a lymphoma-prone family. Cancer 1987; 60: 864-869.

5. Hayoz D, Extermann M, Odermatt BF, Pugin P, Regamey C and Knecht H. Familial primary gastric lymphoma. Gut 1993; 34: 136-140.

6. Zhu K, Levine RS, Gu Y, Brann EA, Hall I, Caplan LS and Baum MK. Non-Hodgkin's lymphoma and family history of malignant tumors in a case-control study (United States). Cancer Causes Control 1998; 9: 77-82.

7. Chang ET, Smedby KE, Hialgrim H, Porwit-MacDonald A, Roos G, Glimelius B and Adami HO. Family history of hematopoietic malignancy and risk of lymphoma. J Natl Cancer Inst 2005; 97 : 1466-1474.

8. Goldin LR, Landgren $O$, McMaster ML, Gridley G, Hemminki K, Li X, Mellemkjaer L, Olsen JH and Linet MS. Familial aggregation and heterogeneity of non-Hodgkin lymphoma in population-based samples. Cancer Epidemiol Biomarkers Prev 2005; 14: 2402-2406.

9. Chatteriee N, Hartge P, Cerhan JR, Cozen W, Davis S, Ishibe N, Colt J, Goldin L and Severson RK. Risk of non-Hodgkin's lymphoma and family history of lymphatic, hematologic, and other cancers. Cancer Epidemiol Biomarkers Prev 2004; 13 : 1415-1421. 
10. Pottern LM, Linet M, Blair A, Dick F, Burmeister LF, Gibson R, Schuman LM and Fraumeni JF Jr. Familial cancers associated with subtypes of leukemia and non-Hodgkin's lymphoma. Leuk Res 1991; 15: 305-314.

11. Altieri A, Bermejo JL and Hemminki K. Familial risk for nonHodgkin lymphoma and other lymphoproliferative malignancies by histopathologic subtype: the Swedish Family-Cancer Database. Blood 2005; 106: 668-72. Epub 2005 Apr 5.

12. Pötzsch C, Schaefer $H$ and Lübbert M. Familial and metachronous malignant lymphoma: absence of constitutional p53 mutations. Am J Hematol 1999; 62: 144-149.

13. Wiernik PH, Wang SQ, Hu XP, Marino P and Paietta E. Age of onset evidence for anticipation in familial non-Hodgkin's lymphoma. Br J Haematol 2000; 108: 72-79.

14. Shugart YY, Hemminki K, Vaittinen P and Kingman A. Apparent anticipation and heterogeneous transmission patterns in familial Hodgkin's and non-Hodgkin's lymphoma: report from a study based on Swedish cancer database. Leuk Lymphoma 2001; 42: 407-415.

15. Zhu K, Levine RS, Brann EA, Gu Y, Caplan LS, Hall I and Baum MK. Risk factors for non-Hodgkin's lymphoma according to family history of haematolymphoproliferative malignancies. Int J Epidemiol 2001; 30: 818-824.

16. Chiu BC, Weisenburger DD, Zahm SH, Cantor KP, Gapstur SM, Holmes F, Burmeister LF and Blair A. Agricultural pesticide use, familial cancer, and risk of non-Hodgkin lymphoma. Cancer Epidemiol Biomarkers Prev 2004; 13: 525-531.

17. Peach HG and Barnett NE. Critical reviews of epidemiological studies of the association between smoking and non-Hodgkin's lymphoma. Hematol Oncol 2001; 19: 67-80. 